\title{
Diagnostic Yield of a Targeted Next- Generation Sequencing Gene Panel for Pediatric-Onset Movement Disorders: A 3-Year Cohort Study
}

\author{
Federica Graziola 1,2, Giacomo Garone 1,3, Fabrizia Stregapede 4,5, Luca Bosco4, \\ Federico Vigevano ${ }^{1}$, Paolo Curatolo ${ }^{2}$, Enrico Bertini ${ }^{4}$, Lorena Travaglini ${ }^{4}$ and \\ Alessandro Capuano ${ }^{1 *}$
}

${ }^{1}$ Movement Disorders Clinic, Department of Neurosciences, Bambino Gesù Children's Hospital, Rome, Italy, ${ }^{2}$ Department of System Medicine, University of Rome Tor Vergata, Rome, Italy, ${ }^{3}$ University Hospital Pediatric Department, Bambino Gesù Children's Hospital, University of Rome Tor Vergata, Rome, Italy, ${ }^{4}$ Department of Neuroscience, Unit of Neuromuscular and Neurodegenerative Disease, Bambino Gesù Children's Hospital, Rome, Italy, ${ }^{5}$ Department of Sciences, Roma Tre University, Rome, Italy

OPEN ACCESS

Edited by:

Merlin G. Butler,

University of Kansas Medical Center,

United States

Reviewed by:

Maria Paola Lombardi,

University of Amsterdam,

Netherlands

Nelson L. S. Tang,

The Chinese University of

Hong Kong, China

*Correspondence:

Alessandro Capuano

alessandro.capuano@opbg.net

Specialty section:

This article was submitted to

Genetic Disorders,

a section of the journal

Frontiers in Genetics

Received: 09 June 2019 Accepted: 24 September 2019

Published: 29 October 2019

Citation:

Graziola F, Garone G, Stregapede F,

Bosco L, Vigevano F, Curatolo $P$,

Bertini $E$, Travaglini $L$ and Capuano $A$ (2019) Diagnostic Yield of a Targeted

Next-Generation Sequencing Gene Panel for Pediatric-Onset Movement

Disorders: A 3-Year Cohort Study

Front. Genet. 10:1026.

doi: 10.3389/fgene.2019.01026
In recent years, genetic techniques of diagnosis have shown rapid development, resulting in a modified clinical approach to many diseases, including neurological disorders. Movement disorders, in particular those arising in childhood, pose a diagnostic challenge. First, from a purely phenomenological point of view, the correct clinical classification of signs and symptoms may be difficult and require expert evaluation. This is because the clinical picture is often a mixture of hyperkinetic and hypokinetic disorders, and within hyperkinetic movement disorders, combined phenotypes are not unusual. Second, although several genes that cause movement disorders in children are now well-known, many of them have only been described in adult populations or discovered in patients after many years of disease. Furthermore, diseases that alter their mechanisms from childhood to adulthood are still little known, and many phenotypes in children are the result of a disruption of normal neurodevelopment. High-throughput gene screening addresses these difficulties and has modified the approach to genetic diagnosis. In the exome-sequencing era, customized genetic panels now offer the ability to perform fast and low-cost screening of the genes commonly involved in the pathogenesis of the disease. Here, we describe a 3-year study using a customized gene panel for pediatriconset movement disorders in a selected cohort of children and adolescents. We report a satisfying diagnostic yield, further confirming the usefulness of gene panel analysis.

Keywords: dystonia, chorea, neurodegeneration with brain iron accumulation disorders, genetics, next-generation sequencing, children, myoclonus, neurotransmitters

\section{INTRODUCTION}

Movement disorders (MDs) are a heterogeneous group of neurological conditions characterized by the production of abnormal voluntary or involuntary movements (Sanger et al., 2010). In children, MDs frequently occur in complex presentations, with different MDs appearing simultaneously or sequentially in the same patient. Frequently, MDs can coexist with other neurological disorders, 
resulting in complex neurodevelopmental conditions (Cordeiro et al., 2018). A systematic approach is needed to reach the correct diagnosis, and the first step usually relies on the phenomenological classification of the disorder (Sanger, 2003; Abdo et al., 2010; O’Malley and Gilbert, 2018).

Many pediatric-onset MDs are monogenic diseases, and their genetic landscape has been widely explored in recent years due to the introduction and spread of next-generation sequencing (NGS) technology. This has had a significant impact on the definition of phenotypes and syndromes. NGS denotes a group of technologies that allow the sequencing of a large amount of nucleic acid, representing an entirely new paradigm in sequencing technology that follows Sanger sequencing (Sanger et al., 1977; Lohmann and Klein, 2014). Using targeted resequencing, a subset of regions of interest on the genome can be sequenced by NGS. This strategy is widely used to sequence selected genes involved in the pathogenesis of specific disease (Reale et al., 2018). Few studies have investigated the diagnostic yield of gene panel analysis in MDs (van Egmond et al., 2017; Montaut et al., 2018; Reale et al., 2018), and molecular investigations in pediatric-onset MDs are highly variable, according to the availability of local resources and the methods of molecular genetics laboratories.

In this study, we retrospectively analyzed the diagnostic performance of a customized, targeted NGS panel specifically designed for pediatric-onset MDs in a large cohort of children referred to our institution.

\section{MATERIALS AND METHODS}

\section{Participants}

This retrospective study was conducted in a cohort of pediatric patients referred to the Movement Disorders Clinic of Bambino Gesù Children's Hospital in Rome, a tertiary referral hospital for rare neurological diseases in children. All patients underwent genetic tests for MDs with the customized NGS panel available at the molecular medicine laboratory in our department. All data available from January 2015 to November 2018 were collected. Electronic patient files were reviewed by pediatric neurologists experienced in MDs, and the phenomenology of the MDs was classified by reviewing video-recorded examinations. Furthermore, the clinical features of MDs, neuroimaging tests, biochemical work-up, and neurophysiological tests (when performed) were reviewed. Inclusion criteria were diagnosis of an MD (including dystonia, chorea, myoclonus, and tremor) with onset before 18 years of age and/or positive family history of an MD and ruling out of secondary causes (such as perinatal asphyxia or cerebral infection) during the diagnostic work-up. Patients with tic disorders or Tourette's syndrome,

\footnotetext{
Abbreviations: AD, autosomal dominant; $\mathrm{AR}$, autosomal recessive; CSF: cerebrospinal fluid; DYT, dystonia; EA, episodic ataxia; EPD, exercise-induced paroxysmal dyskinesia; fHM, familial hemiplegic migraine; HSP, hereditary spastic paraplegias; MAF, minor allele frequency; MD, movement disorders; MRI, magnetic resonance imaging; NBIA, neurodegeneration with brain iron accumulation; NGS, next generation sequencing; NT, inherited disorders of neurotransmitter metabolism; PKD, paroxysmal kinesigenic dyskinesia; PMD, paroxysmal movement disorders; XLD, X-linked; WES, whole exome sequencing.
}

pure cerebellar ataxia, or hereditary spastic paraplegia were excluded, as were patients with incomplete medical records. In addition, patients who underwent the same gene panel analysis for a clinical suspicion of familial hemiplegic migraine (fHM) or childhood periodic syndromes (e.g., paroxysmal torticollis) were not included in the analysis.

The patients were grouped into five categories according to their most prominent MD: isolated dystonia, combined dystonia (when dystonia was associated with other MDs), paroxysmal MDs (PMDs), chorea, and tremor. The PMD group was divided into subgroups using phenomenology and the trigger factors of the attacks. DNA samples of index patients and both parents (trios) were collected from peripheral blood leukocytes using standard procedures. Written informed consent for genetic testing was obtained from patients' legal guardians or directly from the patient for those aged 18 years or older. During the diagnostic work-up, all patients underwent brain Magnetic Resonance Imaging (MRI), and neurophysiological exams, neuropsychological tests, and biochemical studies on blood, urine, and cerebrospinal fluid were performed following a case-by-case clinical assessment.

\section{Targeted Sequencing}

Targeted sequencing of index cases' DNA was performed using a mean of a customized panel (Nextera Rapid Custom Enrichment, Illumina, San Diego, CA), including 102 genes, selected in accordance with the results of a systematic literature review of studies of MD-associated genes. The panel was designed with the Illumina Design Studio tool. The region of interest was the coding sequence of each gene with a \pm 20 bp intronic flanking region to include splicing mutations. The $3^{\prime}$ and $5^{\prime}$ untranslated regions (UTRs) were included in the sequenced region only in genes with previously described pathogenic variants in the UTRs. Gene libraries were obtained from a Nextera Rapid Capture Target Enrichment Kit and sequenced on a MiSeq platform (Illumina). The generated reads were aligned to human genome assembly hg38 (December 2013, GRCh38). Variants were called using the HaplotypeCaller tool of GATK software, version 4.3 (Cambridge, MA, USA) and annotated with the ANNOVAR software tool (Wang et al., 2010). Annotated data were filtered to exclude intronic and synonymous variants that were not predicted to affect splice sites, as well as variants with reported minor allele frequency (MAF) $\geq 0.01$ in publicly available resources on human variation, such as dbSNP ver. 144, 1000 Genomes, Exome Aggregation Consortium (ExAC), NHLBI Exome Sequencing Project Exome Variant Server (EVS). Missense variants of suspected pathogenicity were investigated using in silico prediction tools, including PolyPhen-2 (http:// genetics.bwh.harvard.edu/pph2/), SIFT (http://sift.jcvi.org/), MutationTaster (http://www.mutationtaster.org/), and Alamut (https://www.interactive-biosoftware.com/). Changes affecting the splice site were investigated with Human Splicing Finder (http://www.umd.be/HSF/). Novel variants were considered to be variants of unknown significance when these were rare $(\mathrm{MAF}<$ $0.01 \%$ ) in population databases and/or were predicted not to be pathogenic by prediction tools. Putative pathogenetic variants were validated by Sanger sequencing and investigated in the parents to assess intrafamilial segregation. Possible copy number 
variations were investigated using multiplex ligation-dependent probe amplification or real-time PCR techniques.

\section{RESULTS}

\section{Clinical Characterization of the Cohort}

Overall, 204 patients underwent gene panel analysis for MD and 38 were excluded because they were referred with a clinical diagnosis of fHM or paroxysmal torticollis. Then, 18 patient files were excluded due to incomplete chart documentation. Thus, we included 148 patients in the study, of whom 82 were male (55\%) and 66 were female (45\%). The median age of onset of disease was 8 (range $0-17$ ) years old, and the median age at the time of gene panel analysis was 9.5 (range $0-20$ ) years. A total of 134 cases (93\%) were sporadic (meaning that no other relatives were affected), and the remaining $14(7 \%)$ had a family history of disease. Of the total, 59 patients were investigated for combined dystonia (40\%), 31 for isolated dystonia (21\%), 34 patients for (PMDs) (23\%), 20 for chorea (13\%), and 4 for tremor (3\%) (Figure 1). Among the 34 patients referred for PMD, 10 were investigated for episodic ataxia (EA), 18 for paroxysmal kinesigenic dyskinesia (PKD), 2 for exercise-induced paroxysmal dyskinesia (EPD), 4 for hemiplegic attacks, and 1 for paroxysmal myoclonus (Figure 1). In all, 102 patients (68.9\%) presented neurological features other than MDs (Figure 2A).

\section{Diagnostic Yield}

Pathogenic variants were detected in 42 out of 148 patients, leading to a diagnostic yield of $28 \%$ (Table 1 in the Supplementary Materials), and 106 patients were left without a definite molecular diagnosis after gene panel analysis (Figure 2B). We detected pathogenic variants in 20 of 59 patients in the combined dystonia group (34\%), 5 of 31 in the isolated dystonia group (16\%), 5 of 20 in the chorea group (25\%), and 12 of 34 in the pMD group (35\%,
Figure 2B). Among the pMD patients, the diagnostic rate was $50 \%$ for PKD and EPD patients, 25\% for patients with hemiplegic attacks, and $10 \%$ in those with EA. No pathogenic variants were identified in the only patient with paroxysmal, non-epileptic myoclonic attacks or in the patients investigated for tremor (Figure 2C).

The distribution of the pathogenic variants detected in specific genes is shown in Figure 2D. A total of 28 patients exhibited de novo variants; in the remaining patients, autosomal dominant and autosomal recessive inheritance was found in 11 and 2 patients, respectively. One case was X-linked. Nine patients had a variant in the PRRT2 gene, and eight of those nine carried the classical PRRT2 mutation variant (Chen et al., 2011); in the ATP1A3, $S L C 2 A 1$, and GNAO1 genes, pathogenic variants were detected six, five, and three times, respectively. NKX2-1, ADAR1, ADCY5, $A T P 1 A 2$, and KMT2B were found to be mutated twice each, and CACNA1B, TOR1A, KCTD17, PANK2, PLA2G6, SCN1A, SCN2A, $S T X B P 1$, and $W D R 45$ were found to be mutated one time each. Table 1 summarizes all pathogenic variants detected.

\section{Peculiar Findings}

The application of gene panel analysis allowed previously known phenotypes to be expanded and new genotypes to be detected for several pediatric-onset MDs.

A de novo, previously unreported, heterozygous variant in the GNAO1 gene (c.535A>G, p.Arg179Gly) was found in a male subject with a progressive upper body dystonia with onset in the second decade, first involving the arms and later spreading to the cranio-cervical region. He presented with a moderate intellectual disability and was suffering from partial epilepsy, controlled by therapy with carbamazepine. He had never experienced an episode of acute dystonia exacerbation. Taken together with the findings of a recent report (Kelly et al., 2019), this finding expands the spectrum of GNAO1-related neurological conditions beyond the two most frequently

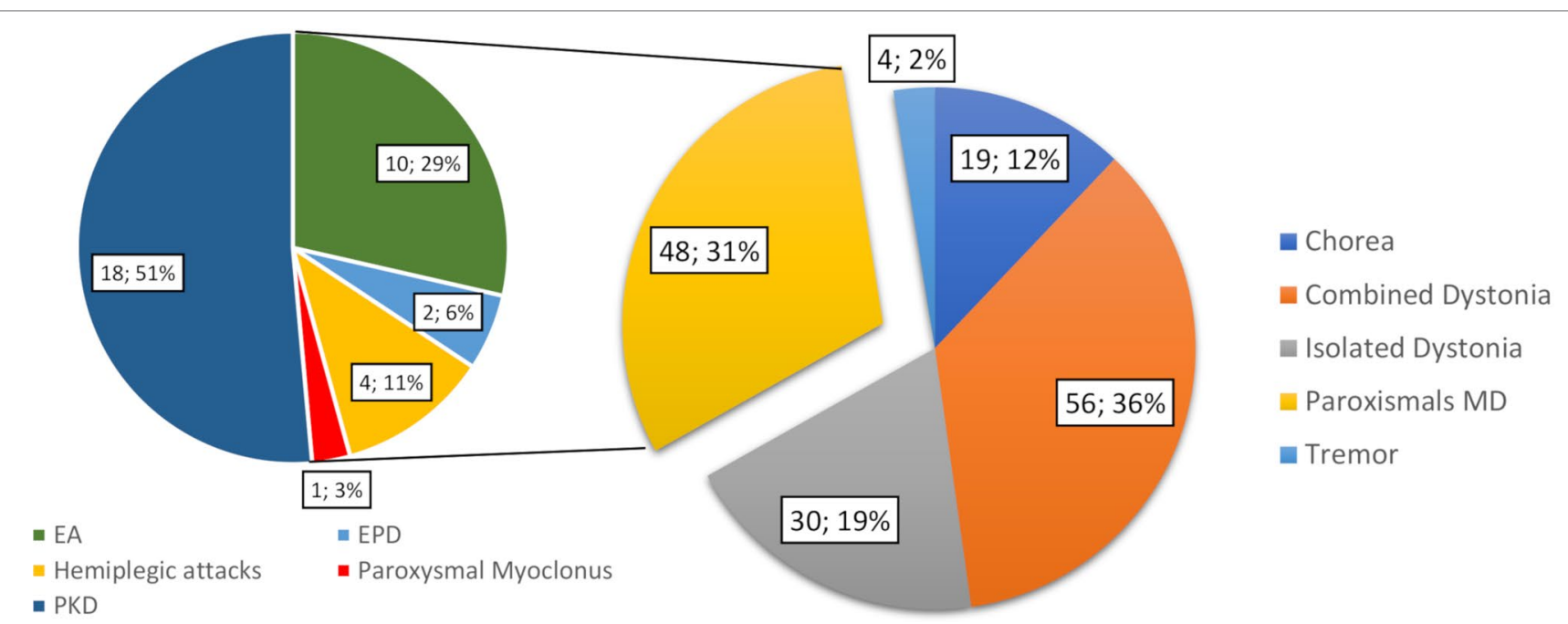

FIGURE 1 | Number and percentage of the total patients by classification according to prominent MD phenomenology. Following the phenomenology of the attacks, the paroxysmal MD group is further classified into episodic ataxia (EA), paroxysmal kinesigenic dyskinesia (PKD), and exercise-induced paroxysmal dyskinesia (EPD), hemiplegic attacks, and paroxysmal myoclonus groups. MD, movement disorder. 


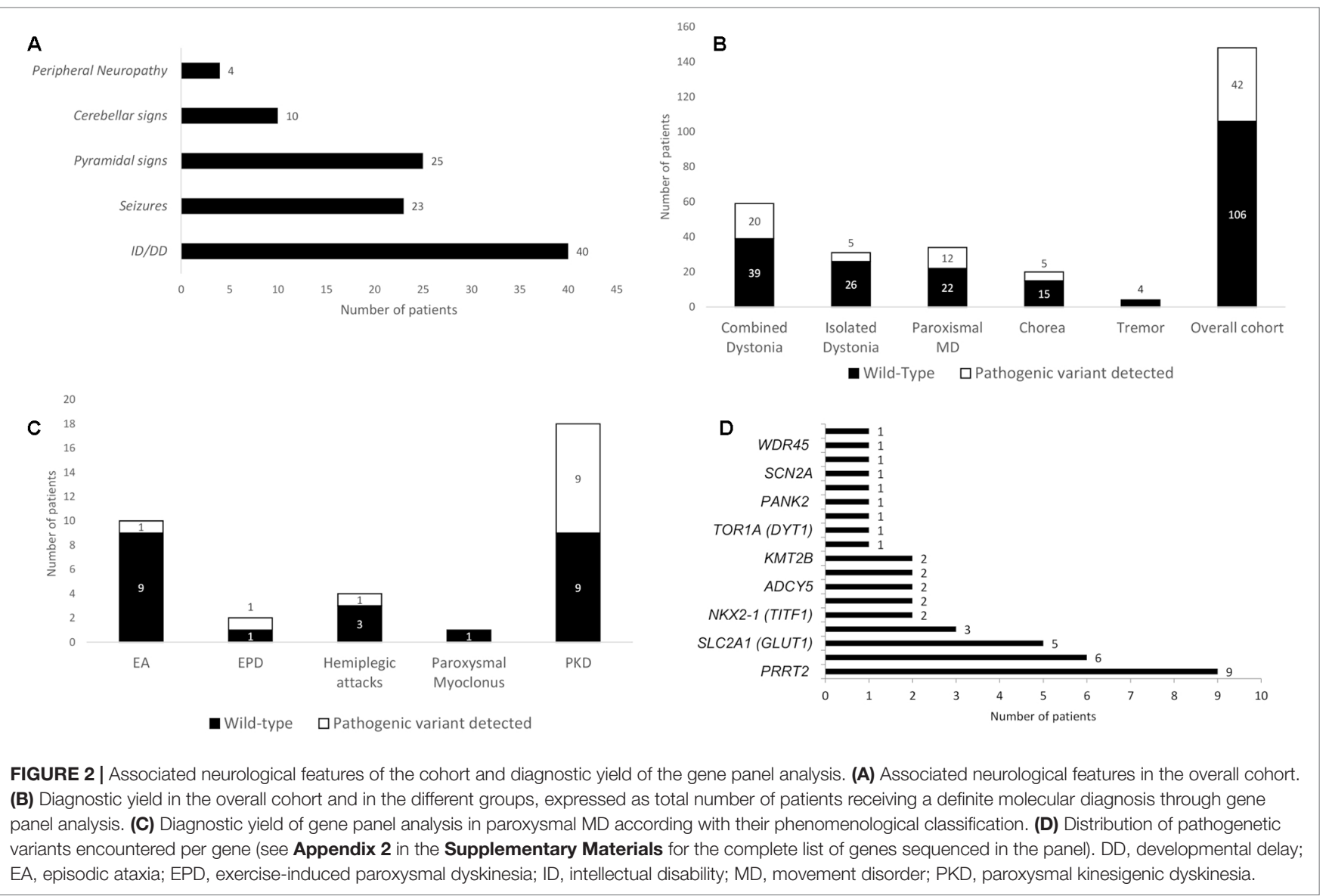

reported and severe phenotypes, namely, early infantile epileptic encephalopathy (EIEE17, OMIM 615473) and earlyonset hyperkinetic phenotype (OMIM 617493) (Schirinzi et al., 2018a).

In addition, we detected a novel heterozygous variant in the KCTD17 gene (c.508-2A>T) in a girl with a childhood-onset complex MD, mainly characterized by myoclonic dystonia. This variant affects the acceptor splice site of the exon 5, unveiling an alternative cryptic site $34 \mathrm{bp}$ downstream and determining the skipping of the first 35 nucleotides of the exon. This results in a shift of the reading frame with a premature stop codon introduction in exon 7 , which causes reduced protein expression (Graziola et al., 2018). This finding was further confirmed by an independent group that described a boy with childhood-onset myoclonus-dystonia harboring a novel KCTD17 variant in an adjacent nucleotide (c.508-1G>C) affecting the same splice site (Marcé-Grau et al., 2019).

Finally, we found a novel, heterozygous missense variant affecting the STXBP1 gene (c.1324A>G, p.N442D) in a 12 -year-old boy with a severe neurodevelopmental disorder characterized by infantile-onset, drug-resistant epilepsy (with generalized myoclonic and focal motor seizures), an intellectual disability, and a peculiar complex MD phenotype with hypokinetic-rigid and dystonic features, with marked fluctuations in severity from day to day. Cerebrospinal fluid (CSF) neurotransmitter analysis revealed low levels of homovanillic and 5-hydroxyindoleacetic acids. First described as causative of a severe early infantile epileptic encephalopathy (EIEE4, OMIM 612164) (Saitsu et al., 2008), the STXBP1 gene is now known to cause a severe neurodevelopmental disorder with almost constant intellectual disability, a high prevalence of epilepsy, and frequent occurrence of various MDs (Stamberger et al., 2016). This previously unreported variant falls within the $3 \mathrm{~b}$ domain of the protein, with missense variants affecting the adjacent codon being already reported in patients with EIEE4 (Stamberger et al., 2016). Despite the numerous reports of STXBP1-encephalopathy, the clinical and biochemical picture of related MD is largely unknown.

\section{DISCUSSION}

Over the last decade, NGS techniques have increasingly been used as a diagnostic tool for rare genetic diseases (Neveling et al., 2013; van Egmond et al., 2017; Cordeiro et al., 2018; Montaut et al., 2018; Reale et al., 2018). To date, few studies have investigated the diagnostic yield of molecular testing in MD (Neveling et al., 2013; van Egmond et al., 2017; Cordeiro et al., 2018; Montaut et al., 2018; Reale et al., 2018). The overall rate of molecular diagnosis in previous studies ranges from $11 \%$ to $51 \%$. However, the results of previous studies are not generalizable, due to heterogeneous study designs, sample sizes, inclusion 
TABLE 1 | All variants detected in our cohort classified on the basis of main phenotype.

\begin{tabular}{|c|c|c|c|c|c|c|c|}
\hline Phenotype & $\begin{array}{l}\text { Gene } \\
\text { (\#MIM number) }\end{array}$ & $\begin{array}{l}\text { Pattern of } \\
\text { inheritance }\end{array}$ & DNA variation & $\begin{array}{l}\text { Amino acid } \\
\text { change }\end{array}$ & $\begin{array}{l}\text { Allele } \\
\text { transmission }\end{array}$ & Segregation & Reference \\
\hline \multirow[t]{5}{*}{ Chorea } & $\begin{array}{l}\text { NKX2.1 } \\
(\# 600635)\end{array}$ & $A D$ & c.344delG & p.G115AfsX9 & het & Sporadic & Novel \\
\hline & & $A D$ & c.391C>T & p.Q131X & het & Familial & Novel \\
\hline & $\begin{array}{l}\text { ADCY5 } \\
\text { (\#600293) }\end{array}$ & $A D$ & c. $2083 \mathrm{C}>\mathrm{G}$ & p.R695G & het & Sporadic & Novel \\
\hline & & $A D$ & c. $1253 \mathrm{G}>\mathrm{A}$ & p.R418Q & het & Sporadic & Chen et al. (2015) \\
\hline & $\begin{array}{l}\text { GNAO1 } \\
(\# 139311)\end{array}$ & $A D$ & c.709G $>A$ & p.E237K & het & Sporadic & Schirinzi et al., 2018a \\
\hline \multirow[t]{25}{*}{ Dystonia } & $\begin{array}{l}\text { ADAR1 } \\
(\# 606601)\end{array}$ & $\mathrm{AR}$ & c. $557 \mathrm{C}>\mathrm{G}+\mathrm{C} .2894 \mathrm{C}>\mathrm{T}$ & $\begin{array}{l}\text { p.P193A+ } \\
\text { p.P965L }\end{array}$ & comp het & Sporadic & $\begin{array}{l}\text { Rice et al. (2012) Wang } \\
\text { et al. (2010) }\end{array}$ \\
\hline & & $A D$ & c. $3019 \mathrm{G}>\mathrm{A}$ & p.G1007R & het & Sporadic & Suzuki et al. (2005) \\
\hline & $\begin{array}{l}\text { ATP1A2 } \\
(\# 182340)\end{array}$ & $A D$ & c. $2335 \mathrm{~A}>\mathrm{C}$ & p.S779R & het & Sporadic & Novel \\
\hline & & $A D$ & c. $889 \mathrm{G}>\mathrm{A}$ & p.A297T & het & Sporadic & Novel \\
\hline & $\begin{array}{l}\text { ATP1А3 } \\
(\# 182350)\end{array}$ & $A D$ & c.2227_2229delGAC & p.D743del & het & Sporadic & Schirinzi et al., 2018b \\
\hline & & $A D$ & c.2266C>T & p.R756C & het & Sporadic & Kanemasa et al. (2016) \\
\hline & & $A D$ & c.2266C >T & p.R756C & het & Familial & Kanemasa et al. (2016) \\
\hline & & $A D$ & c. $2452 \mathrm{G}>\mathrm{A}$ & p.E818K & het & Sporadic & Demos et al. (2014) \\
\hline & & $A D$ & c. $2767 \mathrm{G}>\mathrm{A}$ & p.D923N & het & Sporadic & Anselm et al. (2009) \\
\hline & & $A D$ & c. $2838 \mathrm{G}>\mathrm{C}$ & p.G947R & het & Sporadic & Heinzen et al. (2012) \\
\hline & $\begin{array}{l}\text { CACNA1B } \\
(\# 601012)\end{array}$ & $A D$ & c.5381C>T & p.T1794M & Het & Sporadic & Novel \\
\hline & $\begin{array}{l}\text { TOR1A } \\
(\# 605204)\end{array}$ & $A D$ & c.907_909delGAG & p.E303del & Het & Familial & Ozelius et al. (1997) \\
\hline & $\begin{array}{l}\text { GNAO1 } \\
(\# 139311)\end{array}$ & $A D$ & c. $535 \mathrm{~A}>\mathrm{G}$ & p.R179G & Het & Sporadic & Novel \\
\hline & & $A D$ & c. $607 \mathrm{G}>\mathrm{A}$ & p.G203R & Het & Sporadic & Schirinzi et al., 2018a \\
\hline & $\begin{array}{l}\text { KCTD17 } \\
(\# 616386)\end{array}$ & $A D$ & c. $508-2 A>T$ & & & Sporadic & Graziola et al. (2018) \\
\hline & $\begin{array}{l}\text { КМТ2B } \\
(\# 606834)\end{array}$ & $A D$ & c.1664dupC & p.V557GfsX4 & Het & Sporadic & Novel \\
\hline & & $A D$ & c.649dupC & p.R217fsX34 & Het & Sporadic & Novel \\
\hline & $\begin{array}{l}\text { SCN2A } \\
(\# 182390)\end{array}$ & $A D$ & c. $4951 \mathrm{~T}>\mathrm{G}$ & p.F1651V & Het & Sporadic & Novel \\
\hline & $\begin{array}{l}\text { SLC2A1 } \\
(\# 138140)\end{array}$ & $A D$ & c. $152 \mathrm{G}>\mathrm{A}$ & p.R51H & Het & Familial & Novel (rs201815571) \\
\hline & & $A D$ & c. $458 \mathrm{G}>\mathrm{C}$ & p.R153P & Het & Sporadic & Novel \\
\hline & $\begin{array}{l}\text { SGCE } \\
(\# 604149)\end{array}$ & $A D$ & c.386T>C & p.l129T & Het & Sporadic & Tedroff et al. (2012) \\
\hline & $\begin{array}{l}\text { STXBP1 } \\
(\# 602926)\end{array}$ & $A D$ & c. $1324 \mathrm{~A}>\mathrm{G}$ & p.N442D & Het & Sporadic & Novel \\
\hline & $\begin{array}{l}\text { PANK2 } \\
\text { (\#606157) }\end{array}$ & $\mathrm{AR}$ & c. $1151 \mathrm{C}>\mathrm{A}+\mathrm{C} .444 \_446 \mathrm{delG}$ & $\begin{array}{l}\text { p.P384H+ } \\
\text { p.E148fsX55 }\end{array}$ & comp het & Sporadic & $\begin{array}{l}\text { Novel } \\
\text { Novel }\end{array}$ \\
\hline & $\begin{array}{l}\text { PLA2G6 } \\
(\# 603604)\end{array}$ & $\mathrm{AR}$ & c.607C>T+dupEx 6-7 & $\begin{array}{l}\text { p.Q203X+ } \\
\text { dup6-7 }\end{array}$ & comp het & Sporadic & $\begin{array}{l}\text { Novel } \\
-\end{array}$ \\
\hline & $\begin{array}{l}\text { WDR45 } \\
\text { (\#300526) }\end{array}$ & XLD & c.7C>T & p.Q3X & Het & Sporadic & Novel \\
\hline \multirow[t]{12}{*}{$\begin{array}{l}\text { Paroxysmal } \\
\text { MD }\end{array}$} & $\begin{array}{l}\text { PRRT2 } \\
\text { (\#614386) }\end{array}$ & $A D$ & c. $577 \mathrm{G}>\mathrm{T}$ & p.E193X & Het & Sporadic & Novel \\
\hline & & $A D$ & c.649dupC & p.R217fsX8 & Het & Sporadic & Chen et al. (2011) \\
\hline & & $A D$ & c.649dupC & p.R217fsX8 & Het & Familial & Chen et al. (2011) \\
\hline & & $A D$ & c.649dupC & p.R217fsX8 & het & Familial & Chen et al. (2011) \\
\hline & & $A D$ & c.649dupC & p.R217fsX8 & het & Familial & Chen et al. (2011) \\
\hline & & $A D$ & c.649dupC & p.R217fsX8 & het & Familial & Chen et al. (2011) \\
\hline & & $A D$ & c.649dupC & p.R217fsX8 & het & Familial & Chen et al. (2011) \\
\hline & & $A D$ & c.649dupc & p.R217fsX8 & het & Familial & Chen et al. (2011) \\
\hline & & $A D$ & c.649dupC & p.R217fsX8 & het & Familial & Chen et al. (2011) \\
\hline & $\begin{array}{l}\text { SLC2A1 } \\
(\# 138140)\end{array}$ & $A D$ & c. $275+3 \mathrm{~A}>\mathrm{T}$ & p.R92fsX26 & het & Sporadic & Novel \\
\hline & & $A D$ & c. $972+1 \mathrm{G}>\mathrm{T}$ & - & het & Sporadic & Wang et al. (2000) \\
\hline & & $A D$ & c.1097_1100delATCT & p.Y366X & het & Sporadic & Novel \\
\hline
\end{tabular}

$A D$, autosomal dominant; $A R$, autosomal recessive; $X L D, X$-linked; het, heterozygosis; comp het, compound heterozygosis. 
criteria, and specific diagnostic techniques (Neveling et al., 2013; van Egmond et al., 2017; Cordeiro et al., 2018; Montaut et al., 2018; Reale et al., 2018). To the best of our knowledge, this is the first study to specifically address the diagnostic yield of a customized gene panel for MD in a large pediatric cohort.

Our diagnostic rate of $28 \%$ is slightly higher than the rates reported in previous studies that feature gene panel analysis for $\mathrm{MD}$, where diagnostic rates have ranged from $11 \%$ to $22 \%$ (van Egmond et al., 2017; Montaut et al., 2018; Reale et al., 2018). Even if these differences can be attributed to heterogeneous cohort sizes and variant panel design, this finding suggests that the application of MD gene panels to selected target populations (such as children) can improve their diagnostic yield. Higher diagnostic rates have been reported only in studies with combinations of different genetic investigation approaches, such as direct testing, multiple gene panel analysis, and whole-exome sequencing (Cordeiro et al., 2018). A higher diagnostic rate was found in the PMD group (35\%), similar to the rate reported by Montaut et al. (2018) in a smaller cohort (35\% in 20 patients).

In contrast to previous reports (Montaut et al., 2018; Reale et al., 2018), a relatively high diagnostic rate was found in patients with dystonia (28\%, where both isolated and combined forms are considered), probably reflecting a wider genetic landscape of onset in childhood and adolescence relative to adult-onset dystonia. In addition, the diagnostic rate in combined dystonia was considerably higher than in isolated forms of dystonia $(34 \%$ vs. $16 \%$ ), suggesting a higher yield for gene panel analysis in complex dystonia-plus syndromes.

A diagnostic rate of $25 \%$ was found in samples analyzed for suspicion of genetic chorea, very similar to the report of Montaut et al. (2018). By contrast, the diagnostic rate in patients investigated for tremor was null. There may be two reasons for this finding. First, the smaller sample of patients analyzed for tremor syndromes might drive this result. Second, no gene included in the panel specifically targeted isolated tremor syndromes.

A surprising result for a pediatric cohort was that no pathogenic variant was found in genes involved in the synthesis or transportation of neurotransmitters. No patient undergoing CSF neurotransmitter analysis showed a metabolite profile that could be clearly diagnosed as a primary defect of monoamine or folate metabolism. Only nonspecific changes were found. Secondary neurotransmitter abnormalities are frequently found in children with MDs (García-Cazorla et al., 2007; Tonduti et al., 2015; Burlina et al., 2017), and abnormal patterns suggestive of specific conditions other than primary defects have been recently described (Peall et al., 2017; Papandreou et al., 2018). Nevertheless, most of the commonly encountered secondary neurotransmitters abnormalities still lack a specific diagnostic value. This finding suggests that gene panel analysis has a limited diagnostic yield for the genetic diagnosis of inherited disorders of neurotransmission when biochemical studies are inconclusive. Table 2 summarizes the relevant literature on the topic and shows the divisions in phenotypic groups of the different cohorts.

With regard to the specific findings we encountered, gene panel analysis proved to be a valid method to expand the

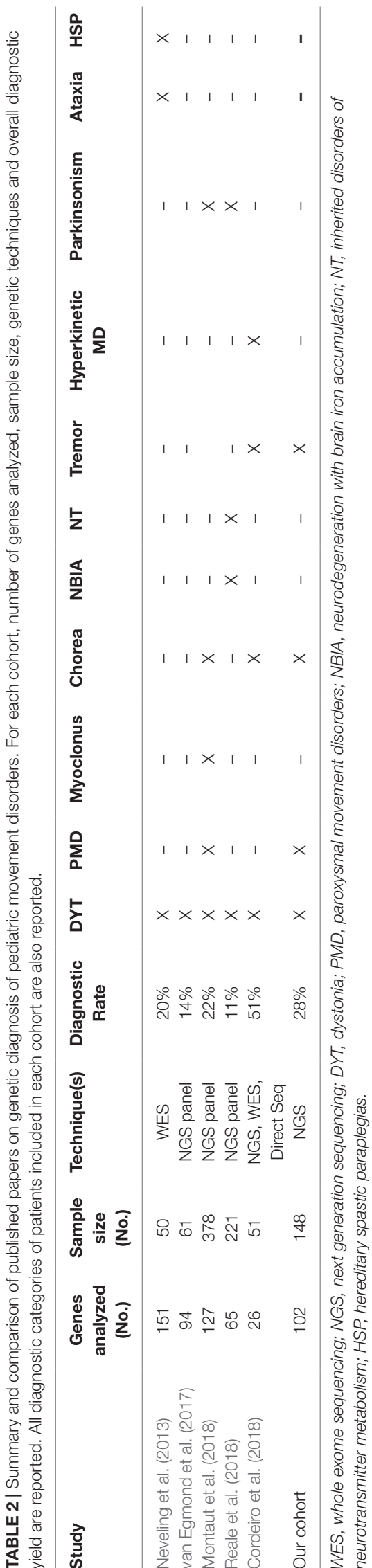


phenotypic and genotypic spectra of $\mathrm{MD}$-associated genes, helping to expand the rapidly growing body of knowledge on recently discovered genes. Taken together, our results underline the extent to which the diagnostic yield of targeted gene panels for MD depends on the selection of patients and the investigation strategies adopted by each diagnostic facility. Nevertheless, targeted panels are a high-throughput sequencing strategy, which is efficient and cost-effective, with a good diagnostic rate. It is recommended that a multiple-strategy approach be adopted to improve the overall diagnostic rate for pediatric-onset MDs. This is necessary, considering the inability to detect copy number variants for these diseases, the low level of mosaicism, and the triplet-repeat expansions through NGS and the occurrence of disorders due to recently discovered or ultra-rare causative genes. A multiple-strategy diagnostic approach should combine target gene sequencing, (multiple) gene panel analysis, molecular cytogenetics, and whole exome or whole genome sequencing in a patient-tailored strategy (Cordeiro et al., 2018). However, the large number of patients with pediatric-onset MD and without a genetic diagnosis for all cohorts reported so far suggests the likely existence of several, still undiscovered, responsible genes (van Egmond et al., 2017; Cordeiro et al., 2018; Montaut et al., 2018; Papandreou et al., 2018; Reale et al., 2018).

From this perspective, gene panel analysis should be proposed as the first diagnostic tool for the genetic investigation of pediatric-onset $\mathrm{MD}$, and the information obtained may be relevant for both diagnostic and research purposes.

\section{DATA AVAILABILITY STATEMENT}

The datasets generated for this study are available on request to the corresponding author.

\section{REFERENCES}

Abdo, W. F., van de Warrenburg, B. P. C., Burn, D. J., Quinn, N. P., and Bloem, B. R. (2010). The clinical approach to movement disorders. Nat. Rev. Neurol. 6, 29-37. doi: 10.1038/nrneurol.2009.196

Anselm, I. A., Sweadner, K. J., Gollamudi, S., Ozelius, L. J., and Darras, B. T. (2009). Rapid-onset dystonia-parkinsonism in a child with a novel atpla3 gene mutation. Neurol. 73, 400-401. doi: 10.1212/WNL.0b013e3181b04acd

Burlina, A. B., Celato, A., Polo, G., Edini, C., and Burlina, A. P. (2017). The utility of CSF for the diagnosis of primary and secondary monoamine neurotransmitter deficiencies. EJIFCC. 28, 64-76.

Chen, D. H., Méneret, A., Friedman, J. R., Korvatska, O., Gad, A., Bonkowski, E. S., et al. (2015). ADCY5-related dyskinesia: broader spectrum and genotype-phenotype correlations. Neurol. 85, 2026-2035. doi: 10.1212/ WNL.0000000000002058

Chen, W. J., Lin, Y., Xiong, Z. Q., Wei, W., Ni, W., Tan, G. H., et al. (2011). Exome sequencing identifies truncating mutations in PRRT2 that cause paroxysmal kinesigenic dyskinesia. Nat. Genet. 43, 1252-1255. doi: 10.1038/ng.1008

Cordeiro, D., Bullivant, G., Siriwardena, K., Evans, A., Kobayashi, J., Cohn, R. D., et al. (2018). Genetic landscape of pediatric movement disorders and management implications. Neurol. Genet. 4, e265. doi: 10.1212/ NXG.0000000000000265

Demos, M. K., van Karnebeek, C. D., Ross, C. J., Adam, S., Shen, Y., Zhan, S. H., et al. (2014). A novel recurrent mutation in ATP1A3 causes CAPOS syndrome. Orphanet. J. Rare. Dis. 9, 15. doi: 10.1186/1750-1172-9-15

\section{ETHICS STATEMENT}

The studies involving human participants were reviewed and approved by Bambino Gesù Local Ethics Committee. Written informed consent to participate in this study was provided by the participants' legal guardians or next of kin.

\section{AUTHOR CONTRIBUTIONS}

FG, GG, FS, and AC contributed to the conception and design of the study; FG and LB organized the database; FG, GG, and AC performed the statistical analysis; FG wrote the first draft of the manuscript; GG, FS, LB, and LT wrote sections of the manuscript; and FV, PC, EB, and AC revised the final draft. All authors contributed to the manuscript revision and read and approved the submitted version.

\section{FUNDING}

This study was partially supported by the Ricerca Corrente funding from the Italian Ministry of Health to IRCCS Bambino Gesù. accumulation; NGS, next generation sequencing; NT, inherited disorders of neurotransmitter metabolism; PKD, paroxysmal kinesigenic dyskinesia; PMD, paroxysmal movement disorders; XLD, X-linked; WES, whole exome sequencing

\section{SUPPLEMENTARY MATERIAL}

The Supplementary Material for this article can be found online at: https://www.frontiersin.org/articles/10.3389/fgene.2019.01026/ full\#supplementary-material

García-Cazorla, A., Serrano, M., Pérez-Dueñas, B., González, V., Ormazábal, A., Pineda, M., et al. (2007). Secondary abnormalities of neurotransmitters in infants with neurological disorders. Dev. Med. Child. Neurol. 49, 740-744. doi: 10.1111/j.1469-8749.2007.00740.x

Graziola, F., Stregapede, F., Travaglini, L., Garone, G., Verardo, M., Bosco, L., et al. (2018). A novel KCTD17 mutation is associated with childhood early-onset hyperkinetic movement disorder. Parkinsonism. Relat. Disord. 61, 4-6. doi: 10.1016/j.parkreldis.2018.12.001

Heinzen, E. L., Swoboda, K. J., Hitomi, Y., Gurrieri, F., Nicole, S., de Vries, B., et al. (2012). De novo mutations in ATP1A3 cause alternating hemiplegia of childhood. Nat. Genet. 44, 1030-1034. doi: 10.1038/ng.2358

Kanemasa, H., Fukai, R., Sakai, Y., Torio, M., Miyake, N., Lee, S., et al. (2016). De novo p.Arg756Cys mutation of ATP1A3 causes an atypical form of alternating hemiplegia of childhood with prolonged paralysis and choreoathetosis. BMC. Neurol. 16, 174. doi: 10.1186/s12883-016-0680-6

Kelly, M., Park, M., Mihalek, I., Rochtus, A., Gramm, M., Pérez-Palma, E., et al. (2019). Spectrum of neurodevelopmental disease associated with the GNAO1 guanosine triphosphate-binding region. Epilepsia. 60, 406-418. doi: 10.1111/ epi.14653

Lohmann, K., and Klein, C. (2014). Next generation sequencing and the future of genetic diagnosis. Neurother. 11, 699-707. doi: 10.1007/s13311-014-0288-8

Marcé-Grau, A., Correa, M., Vanegas, M. I., Muñoz-Ruiz, T., Ferrer-Aparicio, S., Baide, H., et al. (2019). Childhood onset progressive myoclonic dystonia due to a de novo KCTD17 splicing mutation. Parkinsonism. Relat Disord. 61, 7-9. doi: 10.1016/j.parkreldis.2019.01.004 
Montaut, S., Tranchant, C., Drouot, N., Rudolf, G., Guissart, C., Tarabeux, J., et al. (2018). Assessment of a targeted gene panel for identification of genes associated with movement disorders. JAMA. Neurol. 75, 1234-1245. doi: 10.1001/jamaneurol.2018.1478

Neveling, K., Feenstra, I., Gilissen, C., Hoefsloot, L. H., Kamsteeg, E.-J., Mensenkamp, A. R., et al. (2013). A post-hoc comparison of the utility of sanger sequencing and exome sequencing for the diagnosis of heterogeneous diseases. Hum. Mutat. 34, 1721-1726. doi: 10.1002/humu. 22450

O'Malley, J. A., and Gilbert, D. L. (2018). Clinical approach to a child with movement disorders. Semin. Pediatr. Neurol. 25, 10-18. doi: 10.1016/j. spen.2017.12.001

Ozelius, L. J., Hewett, J. W., Page, C. E., Bressman, S. B., Kramer, P. L., Shalish, C., et al. (1997). The early-onset torsion dystonia gene (DYT1) encodes an ATPbinding protein. Nat. Genet. 17, 40-48. doi: 10.1038/ng0997-40

Papandreou, A., Rahman, S., Fratter, C., Ng, J., Meyer, E., Carr, L. J., et al. (2018). Spectrum of movement disorders and neurotransmitter abnormalities in paediatric POLG disease. J. Inherit. Metab. Dis. 41, 1275-1283. doi: 10.1007/ s10545-018-0227-7

Peall, K. J., Ng, J., Dy, M. E., Sharma, N., Pope, S., Heales, S., et al. (2017). Low CSF 5-HIAA in myoclonus dystonia. Mov. Disord. 32, 1647-1649. doi: 10.1002/ mds. 27117

Reale, C., Panteghini, C., Carecchio, M., and Garavaglia, B. (2018). The relevance of gene panels in movement disorders diagnosis: a lab perspective. Eur. J. Paediatr. Neurol. 22, 285-291. doi: 10.1016/j.ejpn.2018.01.013

Rice, G. I., Kasher, P. R., Forte, G. M., Mannion, N. M., Greenwood, S. M., Szynkiewicz, M., et al. (2012). Mutations in ADAR1 cause Aicardi-Goutières syndrome associated with a type I interferon signature. Nat. Genet. 44, 12431248. doi: 10.1038/ng.2414

Saitsu, H., Kato, M., Mizuguchi, T., Hamada, K., Osaka, H., Tohyama, J., et al. (2008). De novo mutations in the gene encoding STXBP1 (MUNC18-1) cause early infantile epileptic encephalopathy. Nat. Genet. 40, 782-788. doi: 10.1038/ ng. 150

Sanger, F., Nicklen, S., and Coulson, A. R. (1977). DNA sequencing with chainterminating inhibitors. Proc. Natl. Acad. Sci. U.S.A. 74, 5463-5467. doi: 10.1073/pnas.74.12.5463

Sanger, T. D. (2003). Pediatric movement disorders. Curr. Opin. Neurol. 16, 529535. doi: 10.1097/01.wco.0000084233.82329.0e

Sanger, T. D., Chen, D., Fehlings, D. L., Hallett, M., Lang, A. E., Mink, J. W., et al. (2010). Definition and classification of hyperkinetic movements in childhood Mov. Disord. 25, 1538-1549. doi: 10.1002/mds.23088

Schirinzi, T., Garone, G., Travaglini, L., Vasco, G., Galosi, S., Rios, L., et al. (2018a). Phenomenology and clinical course of movement disorder in GNAO1 variants: results from an analytical review. Parkinsonism. Relat Disord. 61, 19-25. doi: 10.1016/j.parkreldis.2018.11.019

Schirinzi, T., Graziola, F., Cusmai, R., Fusco, L., Nicita, F., Elia, M., et al. (2018b). ATP1A3-related epileptic encephalopathy responding to ketogenic diet. Brain. Dev. 40, 433-438. doi: 10.1016/j.braindev.2018.01.002

Stamberger, H., Nikanorova, M., Willemsen, M. H., Accorsi, P., Angriman, M., Baier, H., et al. (2016). STXBP1 encephalopathy: A neurodevelopmental disorder including epilepsy. Neurol. 86, 954-962. doi: 10.1212/ WNL.0000000000002457

Suzuki, N., Suzuki, T., Inagaki, K., Ito, S., Kono, M., Fukai, K., et al. (2005). Mutation analysis of the ADAR1 gene in dyschromatosis symmetrica hereditaria and genetic differentiation from both dyschromatosis universalis hereditaria and acropigmentatio reticularis. J. Invest. Dermatol. 124, 11861192. doi: 10.1111/j.0022-202X.2005.23732.x

Tedroff, K., Rolfs, A., and Norling, A. (2012). A novel SGCE gene mutation causing myoclonus dystonia in a family with an unusual phenotype. Acta. Paediatr. 101, e90-e92. doi: 10.1111/j.1651-2227.2011.02502.x

Tonduti, D., Zorzi, G., Ghezzi, D., Zibordi, F., Garavaglia, B., and Nardocci, N. (2015). Cerebrospinal fluid monoamine metabolite analysis in pediatric movement disorders. J. Child. Neurol. 30, 1800-1805. doi: 10.1177/0883073815581608

van Egmond, M. E., Lugtenberg, C. H. A., Brouwer, O. F., Contarino, M. F., Fung, V. S. C., Heiner-Fokkema, M. R., et al. (2017). A post hoc study on gene panel analysis for the diagnosis of dystonia. Mov. Disord. 32, 569-575. doi: 10.1002/ mds. 26937

Wang, D., Kranz-Eble, P., and De Vivo, D. C. (2000). Mutational analysis of GLUT1 (SLC2A1) in Glut-1 deficiency syndrome. Hum. Mutat. 16, 527. doi: 10.1002/1098-1004(200009)16:3<224::AID-HUMU5>3.0.CO;2-P

Wang, K., Li, M., and Hakonarson, H. (2010). ANNOVAR: functional annotation of genetic variants from high-throughput sequencing data. Nucleic. Acids. Res. 38, e164-e164. doi: 10.1093/nar/gkq603

Conflict of Interest: The authors declare that the research was conducted in the absence of any commercial or financial relationships that could be construed as a potential conflict of interest.

Copyright (c) 2019 Graziola, Garone, Stregapede, Bosco, Vigevano, Curatolo, Bertini, Travaglini and Capuano. This is an open-access article distributed under the terms of the Creative Commons Attribution License (CC BY). The use, distribution or reproduction in other forums is permitted, provided the original author(s) and the copyright owner(s) are credited and that the original publication in this journal is cited, in accordance with accepted academic practice. No use, distribution or reproduction is permitted which does not comply with these terms. 